Ensino, Saúde e Ambiente - V8 (2), pp. 13-24, Agosto, 2015

\title{
ELABORAÇÃO DA CARTILHA “A TUBERCULOSE ESTÁ EM CASA. E AGORA?" PARA ORIENTAÇÕES RELACIONADAS À TUBERCULOSE INTRADOMICILIAR
}

\section{ELABORATION OF THE BOOKLET "TUBERCULOSIS IS AT HOME. WHAT SHOULD I DO?" ORIENTATIONS ABOUT INTRADOMICILIARY TUBERCULOSIS}

\author{
Yan Corrêa Rodrigues ${ }^{1}$, Karla Valeria Batista Lima ${ }^{1,2}$, Emilyn Costa Conceição ${ }^{3}$ \\ ${ }^{1}$ Universidade do Estado do Pará, yan.13@ hotmail.com \\ ${ }^{2}$ Instituto Evandro Chagas, Seção de Bacteriologia e Micologia, karlavaleria_2007@hotmail.com \\ ${ }^{3}$ Universidade Federal do Rio de Janeiro, emilyncosta@ gmail.com
}

\section{RESUMO}

Contatos domiciliares, grupo de risco a desenvolver tuberculose (TB), são frequentemente alvos de investigações epidemiológicas. Avaliando a situação nesses ambientes é possível sugerir medidas mais efetivas de prevenção, controle e tratamento da TB. A utilização de estratégias de educação em saúde proporciona desenvolvimento de um aprendizado crítico e científico, e consequentemente, melhora na saúde do paciente. Instrumento suporte nesse processo de aprendizagem são as cartilhas informativas. O objetivo desse trabalho foi apresentar uma cartilha informativa orientada principalmente aos contatos domiciliares. A seleção do conteúdo se deu através de levantamento bibliográfico; e do público alvo considerando estudos epidemiológicos. Após o levantamento, o material foi avaliado por profissionais de saúde e encaminhado para editoração, registro e impressão. A cartilha informativa contém uma historia em quadrinhos usando como cenário o ambiente domiciliar. A disposição textual foi ajustada e prioriza ilustrações. Em seguida, são respondidos questionamentos sobre a doença: O que é TB? Como suspeitar? Como se pega? Quais os sintomas? Como tratar? Como prevenir? E ilustrações relacionadas a cada pergunta foram elaboradas. $\mathrm{O}$ uso de cartilhas pode auxiliar no processo de educação em saúde, de forma a trazer benefícios à saúde dos pacientes.

Palavras-chave: Tuberculose, Cartilha, Contatos domiciliares, Educação em saúde.

\section{ABSTRACT}

Household contacts, risk group to develop tuberculosis (TB), are frequently target of epidemiological investigations. By evaluating the situation in these settings, it is possible to suggest more effective measure regarding prevention, control and treatment of TB. The use of health education strategies provides development of a critical and scientific learning, and consequently improvement in patient health. Support instruments in thus learning process are informative booklets. The objective of this paper was to present an informative booklet targeted mainly to household contacts. Content selection occurred through literature review and target audience considering epidemiological studies. After literature review, the material was evaluated by health professionals and forwarded to publishing, registration and printing. The informative booklet contains a comic using the home environment as backdrop. The textual provision was adjusted and prioritizes illustrations. Then, questions about the disease are answered: What is TB? How to suspect? How do you get? What are the symptoms? How to treat? How to prevent? Illustrations related to each question were prepared. The use of booklets can assist in the health education process, in order to bring benefits to the health of patients.

Keywords: Tuberculosis, Booklet, Household contacts, Health education. 
Ensino, Saúde e Ambiente - V8 (2), pp. 13-24, Agosto, 2015

\section{INTRODUÇÃO}

A Tuberculose (TB) é responsável por infectar grande parcela da população mundial, constituindo um grande problema de saúde pública global, particularmente em regiões em desenvolvimento (MIRANDA et al., 2011). O Brasil ocupa a $16^{a}$ posição no ranking de 22 países que concentram alta carga de TB, esses responsáveis por cerca $80 \%$ dos casos mundiais (WHO, 2014). No país, através do Sistema de Informação de Agravos de Notificação (SINAN) foram notificados 71.123 novos casos e 4700 óbitos, sendo a maioria concentrados nas regiões Norte, Nordeste e Sudeste, as quais apresentam maiores taxas de incidência e mortalidade (BRASIL, 2014).

A transmissão da TB pulmonar ocorre com a inalação de gotículas suspensas no ar, geradas por tosse, espirros e fala, contendo M. tuberculosis (MTB) (CDC, 2011). O risco de infecção está associado a fatores como: o número de organismos em suspensão, a ventilação e iluminação do espaço exposto ao organismo, à duração do tempo que uma pessoa exposta respira o ar contaminado e o estado imune do individuo (ATS, 2005).

Além dos fatores relacionados ao sistema imunológico de cada individuo o adoecimento por TB, muitas vezes, está ligado à pobreza, má distribuição de renda, etilismo, co-infecção com HIV e baixa escolaridade. Assim, alguns grupos populacionais possuem maior vulnerabilidade devido às condições de saúde e de vida a que estão expostos (BRASIL, 2014; SAN PEDRO \& OLIVEIRA, 2013).

Dentre esses grupos, os contatos são considerados grupo vulnerável a desenvolver infecção TB pulmonar, principalmente, devido à prolongada exposição e compartilhamento de fatores de risco ambientais com alguém infectado com MTB (FOX et al., 2012). Geralmente, inclusos nesse grupo estão pessoas do domicilio, familiares, colegas de sala e trabalho, amigos próximos e outros, e por isso são geralmente alvo de estudos epidemiológicos para compreensão da cadeia de transmissão da TB (GUWATUDDE et al., 2003; YAN et al., 2013).

Segundo MOREIRA et al (2003), as investigações epidemiológicas como medidas de controle e prevenção, a utilização de estratégias de educação em saúde proporciona ao paciente o desenvolvimento de um aprendizado crítico e científico, além da conscientização sobre questões, problemas e soluções em saúde.

Educar em saúde combina a obtenção de informações e conhecimentos com o senso de identidade, autonomia, solidariedade e responsabilidade dos indivíduos por sua 
Ensino, Saúde e Ambiente - V8 (2), pp. 13-24, Agosto, 2015

própria saúde e da comunidade; prepara o individuo com metodologias adequadas as suas necessidades, além de prover informações de qualidade sobre a saúde, condições de vida em sua comunidade, de modo que estimula a sua utilização (BRASIL, 2002).

Neves et al. (2010) alertam sobre a insuficiente conscientização e entendimento dos pacientes sobre a TB, fato relacionado à realidade sociocultural. Diante desse panorama, defendem a educação em saúde como estratégia eficaz para intervenções em TB.

As cartilhas são instrumentos utilizados para informar a população, geralmente em campanhas publicitárias utilizando textos didáticos e informativos (MARTEIS et al., 2011). Orientações verbalizadas por profissionais de saúde podem ter como apoio tal ferramenta, ou ainda, servir como um recurso de comunicação baseado na relação dialógica, auxiliando os pacientes a responder dúvidas que possam surgir quando esse não estiver interagindo com um profissional especializado. Quanto a isto, ressalta-se que a reflexão crítica, o diálogo e a construção compartilhada do conhecimento representam ferramentas que propiciam o encontro entre a cultura popular e a científica (BRASIL, 2007).

As ilustrações contidas nas cartilhas possibilitam a reprodução dialogada e reflexiva de diversos aspectos da realidade em que o público-alvo está inserido; facilitam a percepção de detalhes; reduzem ou ampliam o tamanho real dos objetos representados; tornam próximos fatos e lugares distantes no espaço e no tempo e permitem a visualização imediata de processos muito lentos ou rápidos (BACELAR et al., 2003).

Considerando a vulnerabilidade dos contatos domiciliares e a necessidade da aplicação de estratégias saúde em TB, o objetivo do presente artigo foi apresentar a elaboração de uma cartilha informativa orientada principalmente aos contatos domiciliares.

\section{METODOLOGIA}

Inicialmente, visando à confiabilidade do conteúdo apresentado na cartilha, foi realizada a seleção do conteúdo por meio de levantamento bibliográfico em manuais (BRASIL, 2011), websites (BRASIL, 2014. CDC, 2015), diversos artigos científicos relacionados à saúde pública e TB (CRAMPIN et al., 2006; DICK \& LOMBARD, 1997; FOX et al., 2012; MA et al., 2014; ZELNER et at., 2014), e também através de 


\section{Ensino, Saúde e Ambiente - V8 (2), pp. 13-24, Agosto, 2015}

informações obtidas diretamente de profissionais da saúde que atendem pacientes em tratamento.

A cartilha informativa foi direcionada aos contatos domiciliares. A escolha desse público-alvo considerou: (I) estudos epidemiológicos que demonstram maiores índices de transmissão de TB entre contatos domiciliares (CRAMPIN et al., 2006; MA et al., 2014; YAN et al., 2013); (II) deficiência nas percepções dos pacientes sobre a doença (NEVES et al., 2010) e (III) importância na aderência e correta condução do tratamento (BRASIL, 2011; ORR, 2011; ZELNER et at., 2014).

Após a compilação das informações, a equipe envolvida na produção, juntamente com um especialista em design, apresentou propostas para construção do enredo e organização de conteúdo. Recomendações apresentadas em artigos científicos que discutem o arranjo de ilustrações, layouts, diagramação, linguagem e conteúdo também foram consideradas (CABRERA et al., 2002; MOREIRA et al., 2003; WHITTINGHAM et al., 2008).

Para garantir que o conteúdo e disposição do material eram coerentes e precisos, submetemos à avaliação por um grupo de quatro profissionais em saúde pública: Três integrantes (uma médica, uma enfermeira e uma assistente social) da Coordenação Estadual do Programa de Controle da Tuberculose/Secretaria de Saúde do estado do Pará - SESPA, e uma pesquisadora em saúde pública e TB, da Seção de Bacteriologia e Micologia do Instituto Evandro Chagas - SABMI/IEC. A seleção destes profissionais em saúde como avaliadores considerou: (I) atuação em serviços de assistência e atendimento direto aos pacientes com TB; (II) Desenvolvimento de atividades relacionadas a promoção da saúde e TB e (III) conhecimentos aprofundados sobre epidemiologia, diagnostico e tratamento da TB. A cartilha também foi avaliada por um especialista em língua portuguesa para correções e adequação da linguagem empregada na cartilha.

Após as sugestões dos profissionais e revisão final de conteúdo e linguagem, a cartilha foi encaminhada a uma editora para editoração final, registro e impressão do material.

\section{RESULTADOS}

A versão final da cartilha (Figura 1) tem na sua dimensão $15 \times 21 \mathrm{~cm}, 20$ páginas frente e verso, com tiragem da primeira edição de 2000 exemplares e registro ISBN: 978-85-63312-57-0. O material foi dividido em duas partes: (I) pequena historia em 
quadrinhos sobre a TB em ambiente domiciliar e (II) informações e suas respectivas ilustrações relacionadas à TB.

Figura 1: Capa da cartilha informativa.

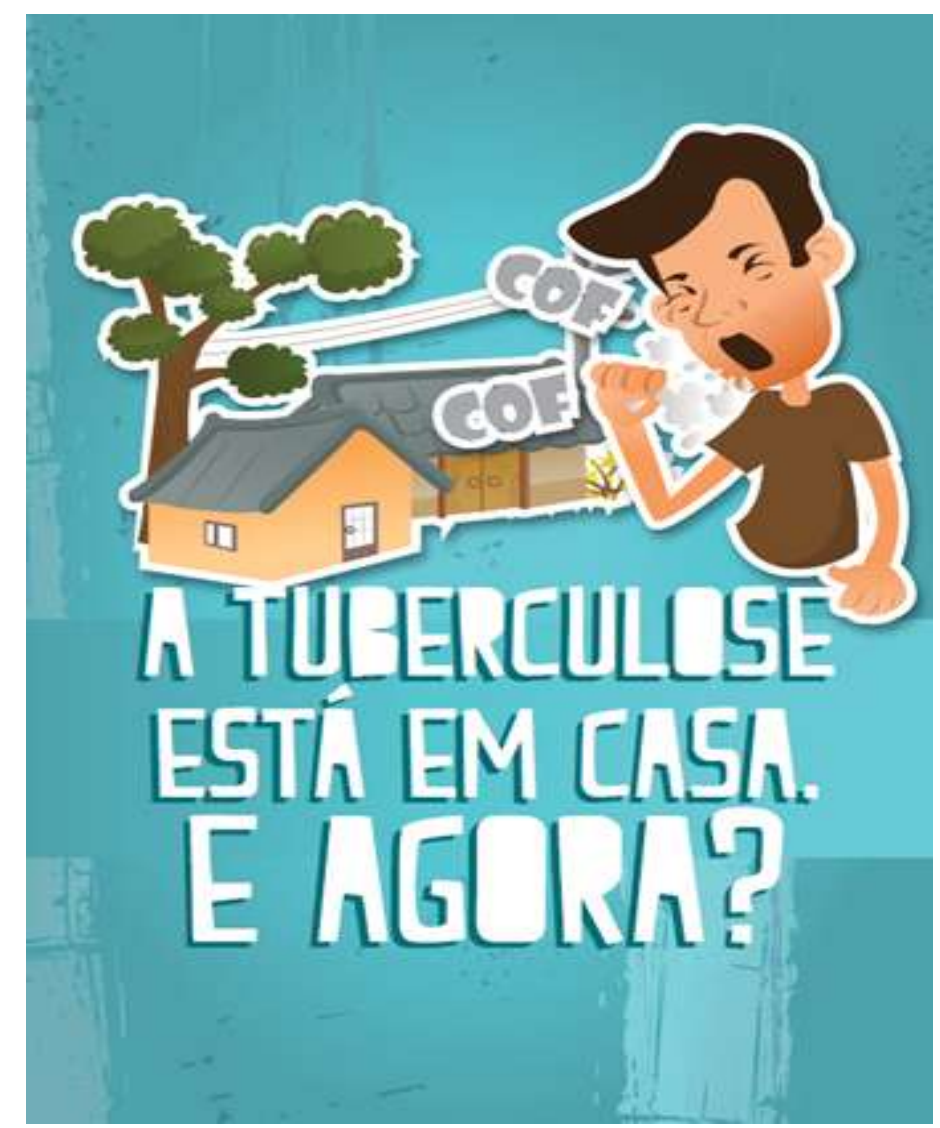

Fonte: Cartilha informativa “A TUBERCULOSE ESTÁ EM CASA. E AGORA?”.

Iniciamos a cartilha com uma breve apresentação e em seguida uma historia em quadrinhos, com seis personagens (Médico, Dona Maria, Sr. João, Dona Flora, o Filho e a Filha), sobre a TB em meio intradomiciliar. A disposição textual é reduzida, com textos ainda mais diretos e ilustrações retratando as situações em família.

O quadrinho inicia com a personagem Dona Maria comparecendo ao posto de saúde, pois seu marido havia iniciado o tratamento para TB e o Médico havia convidado seus familiares para uma consulta. O Médico explica que é importante os familiares comparecerem ao posto de saúde para realizarem exames e talvez um tratamento preventivo, pois estão em contato constante com uma pessoa doente. O Médico também relata a Dona Maria um caso de TB em outro domicilio.

A situação se passa com personagem "Sr. João", feirante que lida diariamente com varias pessoas. Ele é apresentado com sintomas de tosse, por três semanas, febre, falta de apetite, emagrecimento, cansaço e fraqueza. Sua esposa fica preocupada e 
decidem ir ao Posto de Saúde mais próximo se consultar e para saber o que o Sr. João tem. No posto de saúde, o Médico solicita um exame de escarro, pois havia a suspeita de TB. Infelizmente, o resultado é apresentado como positivo para TB, e ele logo mais inicia o tratamento. O Médico também solicita que toda a família volte ao posto de saúde para fazer exames. O restante da família retorna para realizar os exames da Prova Tuberculínica e o Raio-X do pulmão. Os resultados sugeriram que a esposa e o filho mais velho deveriam iniciar um tratamento (diferente daquele do Sr. João) para evitar que eles tivessem a doença, mas somente o Filho inicia o tratamento preventivo, pois Dona Flora não aceitou fazê-lo. Não foi preciso fazer este tratamento preventivo para a Filha porque os exames foram negativos.

É reforçado pelo Médico que a TB é uma doença curável em praticamente 100\% dos casos novos, sensíveis aos medicamentos anti-TB, desde que o tratamento seja obedecido a rigor (diariamente e regularmente). Fala também para arejarem bem a casa, se possível, não dormirem no mesmo quarto, se alimentarem bem, seguirem corretamente o tratamento e que os remédios são de graça.

Nesse momento, apresentamos Sr. João e o Filho que seguem a risca o tratamento, tomando os remédios no horário certo e sem falta, e Dona flora apresentando os sintomas da TB dois anos depois. Alertamos que se ela tivesse feito o tratamento preventivo a doença poderia ser evitada. Assim, com o tratamento correto, a família foi curada e a casa ficou livre da TB.

De volta ao consultório, o Médico alerta que a doença pode ser transmitida pela fala, tosse ou espirro e que as pessoas mais próximas ao doente ficam mais suscetíveis a adquirir à doença. Reitera que o tratamento preventivo é simples, e tem como objetivo diminuir o risco de transmissão e então convida Dona Maria a realizar os exames.

Por fim, Dona Maria afirma que irá convidar todos de sua casa para realizar os exames, iniciar o tratamento preventivo caso necessário e que irar cuidar de seu esposo para que a TB não fique mais em sua casa.

$\mathrm{Na}$ segunda parte, a cartilha informativa foi disposta de forma a responder questões como: O que é TB? Quais os sintomas? Como tratar? Como se pega? Como prevenir? O que a família deve fazer? Relacionada a cada pergunta foram elaboradas ilustrações associadas com aspectos da realidade (Figura 2). 
Figura 2: Questões abordadas na parte informativa da cartilha.
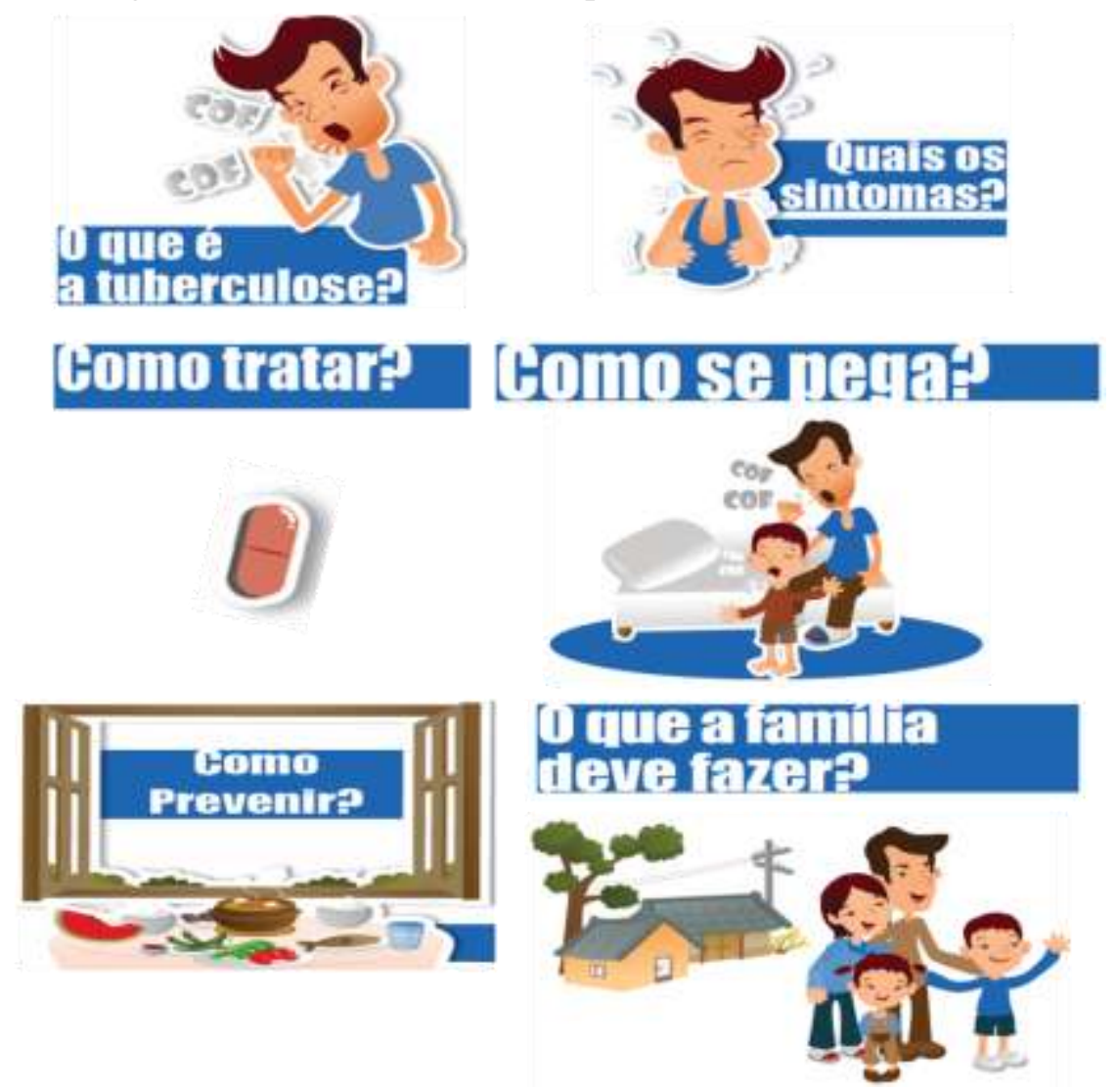

Fonte: Cartilha informativa “A TUBERCULOSE ESTÁ EM CASA. E AGORA?”

Iniciamos o conteúdo informativo, com uma breve apresentação da TB como uma doença contagiosa, transmitida pelo ar e causada por uma bactéria chamada "Mycobacterium tuberculosis". Em seguida são apresentados os principais sintomas: tosse com ou sem escarro (expectoração) por mais de três semanas, febre (mais comumente ao entardecer), suores noturnos, falta de apetite, emagrecimento, indisposição e mal-estar.

Indicamos a suspeita de TB se o individuo apresentar os principais sintomas, e sugerimos a imediata procura por um Posto de Saúde para realizar o exame de escarro para confirmar se o paciente realmente tem TB.

Destacamos que o tratamento da doença tem duração de seis meses, no mínimo, com medicamentos que são distribuídos gratuitamente nos postos de saúde. Enfatizamos que mesmo como uma aparente melhora no primeiro mês, o tratamento não deve ser interrompido ou conduzido de forma irregular, pois os sintomas voltam e as bactérias podem ser tornar resistentes aos medicamentos.

Esclarecemos que a transmissão pode ocorrer quando uma pessoa com TB pulmonar tosse, fala ou espirra próximo a alguém que pode inspirar para seu pulmão a 
gotículas de ar contendo a bactéria; o contato direto e intenso com o doente em ambientes fechados com pouca ventilação e luz solar aumentam as chances de contágio; Deixamos claro que não "se pega" TB bebendo no copo ou utilizando o mesmo talher do paciente, desde que bem lavados; que as pessoas com diabetes, infectadas pelo vírus da AIDS, com precárias condições de vida, desnutrição, alcoolismo e câncer tendem a desenvolver a TB.

Citamos algumas medidas de prevenção da TB, essas também relacionadas ao ambiente familiar foram expostas. Descrevemos que o tratamento dos doentes é a melhor forma de se evitar a disseminação da TB, isso associado ao diagnostico rápido, reduz-se as chances de disseminação da doença no ambiente. Ressaltamos também que as condições da habitação são importantes, manter a casa limpa, ventilada e iluminada pelo sol ajuda a evitar o contagio; que uma aba alimentação torna-se fundamental para diminuição do risco de adoecimento e aumenta a possibilidade de cura; A vacina BCG (bacilo de Calmette-Guérin), aplicada em crianças recém-nascidas, não protege contra a doença, mas evita formas graves da TB.

Para finalização da parte informativa, destacamos que a família é de suma importância no tratamento, pois caso seja confirmado a TB em alguém da casa, todas as pessoas que moram na mesma devem: Ir ao Posto de Saúde também para fazer a Prova Tuberculínica (PPD) e também o Raio-X; Fazer o tratamento preventivo com o mesmo rigor do tratamento para TB (tomar os medicamentos todos os dias e no horário certo); Apoiar e incentivar o doente em seu tratamento e em todos os aspectos.

\section{DISCUSSÃO}

A educação em saúde é qualquer combinação de experiências de aprendizagem destinados a ajudar os indivíduos e as comunidades a melhorar sua saúde, aumentando o seu conhecimento ou influenciando suas atitudes (WHO, 2013). Com apoio de metodologias educacionais, como as cartilhas, se facilita o desenvolvimento criticoreflexivo de um conhecimento sobre saúde (SÁ et al., 2013). No presente artigo apresentamos cartilha informativa "A TUBERCULOSE ESTÁ EM CASA. E AGORA?" como metodologia suporte na construção de conhecimentos sobre TB.

O percurso metodológico para construção da cartilha iniciou-se com uma revisão de literatura, a qual contribuiu para atualização, levantamento de conteúdo científico sobre TB; assegurando a apresentação de informações fidedignas e possibilitando a construção de ideias sobre os pontos a serem abordados na cartilha. 


\section{Ensino, Saúde e Ambiente - V8 (2), pp. 13-24, Agosto, 2015}

Estudos direcionados a contatos, principalmente aos domiciliares, são relevantes, pois através deles é possível avaliar a situação da TB em ambientes com presença de pacientes infectados e, consequentemente, propor medidas para prevenção e interrupção da cadeia de transmissão de TB (GUWATUDDE et al., 2003; ATS, 2005).

Os profissionais de diversas áreas forneceram contribuições importantes para avaliação da precisão e adequação de conteúdo, modificações referentes à escrita e ilustrações, bem como analise critica do material como um todo e de sua relevância para saúde e TB. A participação de diferentes profissionais na elaboração de cartilhas, aplicando seus conhecimentos específicos é defendido e apresentado em outros artigos relacionados à construção de materiais educativos (OLIVEIRA et al. 2014; REBERTE et al. 2012; CABRERA et al., 2002).

Fox et al (2012) defende que a chave para diminuição da transmissão da TB no ambiente domiciliar seria a implementação de estratégias efetivas para auxilio no diagnostico e tratamento adequado dos contatos. Estratégias de educação bem sucedidas requerem seleção de métodos e materiais prestem atenção às limitações educacionais, desafios linguísticos e questões culturais sensíveis e realidade socioeconômica (CABRERA et al., 2002). Dessa forma, para elaboração da cartilha priorizamos o emprego linguagem escrita simplificada e ilustrações, considerando as condições reais da vida dos pacientes (SAN PEDRO \& OLIVEIRA, 2013).

É notável a escassez de materiais educativos direcionados à população. As publicações do Ministério da Saúde (BRASIL, 2011) abordam a TB de forma muito técnica e tem como público-alvo, principalmente, os profissionais de saúde. Os poucos materiais educativos elaborados para população não tem como foco principal a TB no ambiente domiciliar, sendo assim, o material apresentado neste trabalho dirige-se a este último grupo, fornecendo informações gerais sobre a doença.

Estudos conduzidos em outros países demonstraram que com auxilio de intervenções educativas os pacientes melhor compreenderam as informações sobre TB, além de notável melhora no que diz respeito ao abandono e aderência ao tratamento. Dick \& Lombard (1997), na África do Sul, avaliaram a relação da abordagem sobre educação em saúde e aderência ao tratamento da TB em duas clinicas de saúde (uma que sofre intervenção e uma controle). Com amparo de uma cartilha educativa, notaramse diminuição nos índices de abandono ao tratamento na clinica que sofreu intervenção se comparada a clinica controle. 
Os materiais educativos, a exemplo das cartilhas, não se apresentam como um mero reforço ao discurso médico, todavia, são um recurso para a promoção dialógica da saúde utilizando-se da linguagem simples (popular) com o objetivo de fomentar no leitor a reflexão e a criticidade a partir das informações contidas no material. Dessa forma, a alfabetização em saúde funciona como uma construção contínua, quanto maior o fortalecimento desse processo, melhores serão os reflexos na saúde do paciente (APOLINARIO et al., 2012).

\section{CONSIDERAÇÕES FINAIS}

O presente artigo buscou apresentar o processo de construção de uma cartilha direcionada à educação em saúde e TB, sendo está elaborada para prover informações mínimas sobre a TB e a prevenção desta entre contatos domiciliares. A cartilha também objetivou promover a melhora das condições de saúde do paciente e de sua família, auxiliando na superação de obstáculos e dificuldades relacionadas à doença no ambiente domiciliar, através de uma perspectiva crítica, reflexiva e dialógica.

A distribuição da cartilha será em parceria com a Secretaria de Saúde do Estado do Pará (SESPA) e outro estudo será conduzido para avaliar o impacto do material sobre o tratamento e desfecho dos casos, bem como a procura de Unidades de Saúde pelos contactantes.

\section{AGRADECIMENTOS}

Programa de Pós-Graduação Biologia Parasitária na Amazônia/ UEPA e IEC; Coordenação Estadual do Programa de Controle da Tuberculose/SESPA; Referência Estadual do Programa de Controle da Tuberculose - SESPA/HUJBB; Instituto de Desenvolvimento Sustentável Mamirauá; à especialista em língua portuguesa Glauce de Nazaré Souza de Miranda Furtado, pela revisão ortográfica e gramatical do manuscrito; Ao Dr. Manuel Ayres, por sua prontidão ao colaborar para o registro e impressão da primeira edição da cartilha.

\section{REFERÊNCIAS}

AMERICAN THORACIC SOCIETY (ATS). Diagnostic Standards and Classification of Tuberculosis in Adults and Children. American journal of respiratory and critical care medicine, n. 172, p.1169-1227, 2005.

APOLINARIO, D. et al. Short assessment of health literacy for portuguese-speaking adults. Revista de Saúde Pública,v.46, n.4, p.702-711, 2012. 
BACELAR, B.M.F. et al. Metodologia para elaboração de cartilhas em projetos de educação ambiental em micro e pequenas empresas. Recife (PE): JEPEX, 2009.

BRASIL. MINISTÉRIO DA SAÚDE. Fundação Nacional de saúde. Centro de Referência Prof. Hélio Fraga. Controle da Tuberculose: uma proposta de integração ensino-serviço. $5^{\text {a }}$ edição. Rio de Janeiro. Sociedade Brasileira de Pneumologia e Tisiologia. 2002.

BRASIL, MINISTÉRIO DA SAÚDE. Caderno de educação popular e saúde, 2007. Disponível em:

〈http://bvsms.saude.gov.br/bvs/publicacoes/caderno_educacao_popular_saude_p1.pdf> Acessado em Agosto de 2015.

BRASIL, MINISTÉRIO DA SAÚDE. Secretaria de Vigilância em Saúde. Departamento de Vigilância Epidemiológica. Manual de recomendações para o controle da tuberculose no Brasil. Brasília, 2011.

BRASIL, MINISTÉRIO DA SAÚDE. Secretaria de Vigilância em Saúde. Boletim Epidemiológico, v.45, n.2, 2014.

BRASIL, MINISTÉRIO DA SAÚDE. Populações vulneráveis, 2014. Disponível em: $<$ http://portalsaude.saude.gov.br/index.php/o-ministerio/principal/leia-mais-oministerio/743-secretaria-svs/vigilancia-de-a-a-z/tuberculose/12-tuberculose/11941viajantes-tuberculose> Acessado em Agosto de 2015.

CABRERA, D.M. et al. Development of a tuberculosis educational booklet for Latino immigrant patients. Patient Education and Counseling, v.46, p.117-124. 2002.

CENTER FOR DISEASE CONTROL (CDC) - TB ELIMINATION. Tuberculosis: General Information. National Center for HIV/AIDS, Viral Hepatitis, STD, and TB Prevention.Division of Tuberculosis Elimination. 2011.

CENTER FOR DISEASE CONTROL (CDC). Tuberculosis, 2015. Disponível em $<$ http://www.cdc.gov/tb/2015> Acessado em Agosto de 2015.

CRAMPIN, A.C. et al. Tuberculosis transmission attributable to close contacts and HIV status, Malawi. Emerging infectious diseases, v.12, n .5, p.729-735, 2006.

DICK, J.; LOMBARD, C. Shared vision - a health education project designed to enhance adherence to anti-tuberculosis treatment. The International Journal of Tuberculosis and Lung Disease, v. 1, n. 2, p. 181-186, 1997.

FOX, G.J. et al. Contact investigation in households of patients with tuberculosis in Hanoi, Vietnam: a prospective cohort study. PloS one, v. 7, n. 11, p. e49880, 2012.

GUWATUDDE, D. et al. Tuberculosis in household contacts of infectious cases in Kampala, Uganda. American Journal of Epidemiology, v. 158, n. 9, p. 887-898, 2003.

MA, N. et al. Clinical and epidemiological characteristics of individuals resistant to $M$. tuberculosis infection in a longitudinal TB household contact study in Kampala, Uganda. BMC infectious diseases, v. 14, n. 1, p. 352-362, 2014. 
MARTEIS, L. S. et al. Abordagem sobre Dengue na educação básica em Sergipe: análise de cartilhas educativas. Scientia Plena, v. 7, n. 6, 2011.

MIRANDA, S.S. et al. Spoligotyping of clinical Mycobacterium tuberculosis isolates from the state of Minas Gerais, Brazil. Memórias do Instituto Oswaldo Cruz, v. 106, n. 3, p. 267-273, 2011.

MOREIRA, M.F. et al. Comunicação escrita: contribuição para a elaboração de material educativo em saúde. Revista Brasileira de Enfermagem, v. 56, n. 2, p. 184-188, 2003.

NEVES, S.C. et al. Educação em saúde: uma estratégia para minimizar o abandono do tratamento da tuberculose em pacientes do instituto de pesquisa clínica Evandro Chagas/FIOCRUZ. Ensino, Saúde e Ambiente, v.3, n. 3, p. 96-115, 2010.

OLIVEIRA, S.C. et al. Construção e validação de cartilha educativa para alimentação saudável durante a gravidez. Revista Latino-Americana de Enfermagem, v. 22, n. 4, p. 611-620, 2014.

ORR, PAMELA. Adherence to tuberculosis care in Canadian Aboriginal populations Part 2: a comprehensive approach to fostering adherent behavior. International Journal of Circumpolar Health, v. 70, n. 2, p. 128-140, 2011.

REBERTE, L. M. et al. O processo de construção de material educativo para a promoção da saúde da gestante. Revista Latino-Americana de Enfermagem, v. 20, n. 1, p. 101-8, 2012.

SÁ, L.D. et al. Educação em saúde no controle da tuberculose: perspectiva de profissionais da estratégia Saúde da Família. Revista Eletrônica de Enfermagem, v. 15, n. 1, p. 103-111, 2013.

SAN PEDRO, A.; OLIVEIRA, R.M. Tuberculose e indicadores socioeconômicos: revisão sistemática da literatura. Revista Panamericana de Salud Pública, v. 33, n. 4, p. 294-301, 2013.

WHITTINGHAM, J. R. et al. Designing effective health education materials: experimental pre-testing of a theory-based brochure to increase knowledge. Health education research, v. 23, n. 3, p. 414-426, 2008.

WORLD HEALTH ORGANIZATION (WHO). Global Tuberculosis Control, 2014. Disponível em: <http://www.who.int/tb/publications/global_report/en/>. Acessado em Setembro de 2014.

WORLD HEALTH ORGANIZATION (WHO). Tuberculosis, 2013. Disponível em: <http://www.who.int/topics/tuberculosis/en/>. Acessado em Setembro de 2014.

YAN, L. et al. Transmission of extensively drug-resistant and multidrug resistant Mycobacterium tuberculosis in families identified by genotyping. Chinese medical journal, v. 126, n. 3, p. 521-525, 2013. 
Ensino, Saúde e Ambiente - V8 (2), pp. 13-24, Agosto, 2015

ZELNER, J. L. et al. Bacillus Calmette-Guérin and isoniazid preventive therapy protect contacts of patients with tuberculosis. American journal of respiratory and critical care medicine, v. 189, n. 7, p. 853-859, 2014. 